\title{
Phase Distribution for Subcooled Flow Boiling in an Inclined Circular Tube
}

\author{
Wei Bao $(\mathbb{D}$, JianJun Xu $(\mathbb{D}$, TianZhou Xie, BingDe Chen, YanPing Huang, \\ and DianChuan Xing
} CNNC Key Laboratory on Nuclear Reactor Thermal Hydraulics Technology, Nuclear Power Institute of China,
Chengdu 610041, China

Correspondence should be addressed to JianJun Xu; xujjun2000@sohu.com

Received 28 September 2017; Revised 6 December 2017; Accepted 4 January 2018; Published 15 March 2018

Academic Editor: Zhonghao Rao

Copyright () 2018 Wei Bao et al. This is an open access article distributed under the Creative Commons Attribution License, which permits unrestricted use, distribution, and reproduction in any medium, provided the original work is properly cited.

\begin{abstract}
An experimental investigation of phase distribution for subcooled flow boiling in an inclined circular tube (i.d. $24 \mathrm{~mm}$ ) was conducted in this paper. The local interfacial parameters were measured by a double-sensor optical fiber probe, and the measurements were performed on three different directions in the inclined tube cross section. The experiment shows that the phase distribution under the inclined condition is different from the phase distribution under the vertical condition. The profiles skewed highly for $90^{\circ}$ and $45^{\circ}$ direction in the tube cross section, whereas the profile was also symmetrical at $0^{\circ}$ direction. These results can be explained by the fact that buoyancy caused the bubbles to move toward the top of the tube cross section under inclined condition. In addition, the typical distributions were also influenced by the inclination angles.
\end{abstract}

\section{Introduction}

Subcooled flow boiling often appears in industrial fields, such as nuclear reactors, chemical plants, and some engineering systems. With the deepening of the research on the twophase flow and boiling heat transfer, it has been found that distribution of the local interfacial parameter has an important influence on the flow and heat transfer characteristics of the two-phase flow, and the capability to predict the local void distribution in subcooled flow boiling is of great importance for the safety of boiling water reactor. Meanwhile, the establishment and development of the two-fluid model also require the verification with the experimental data of the local interfacial parameters. Therefore, the study on the phase distribution characteristics of the subcooled flow boiling is of great significance to the understanding of the mechanism of two-phase flow and heat transfer.

The local void fraction and interfacial area concentration (IAC) is the basic parameter determining the structure of the two-phase flow. In order to obtain a more reliable interfacial area transport equation, some experiments for the phase distribution of local parameters in two-phase flow are indispensable. Over the past few years, a large number of the experiments regarding gas-liquid bubbly flow have been performed [1-8]. Revankar and Ishii [9] observed that the local IAC appears as a wall-peak profile in a vertical tube. In studies by Hibiki and Ishii [10], Hibiki et al. [11], and Shen et al. [12], four kinds of typical profiles of local interfacial parameters including wall peak, core peak, intermediate peak, and transition have been found in the studies.

A large number of the experiments regarding subcooled flow boiling have been performed. Some tasks for different geometrical channels have been already conducted by the previous investigators. Sekoguchi et al. [13] have used the single-sensor conductivity probe to measure both radial and axial distributions of local fraction under a subcooled boiling condition in a circular tube. Garnier et al. [14] performed the measurements of local interfacial parameters in R-12 subcooled flow boiling in a vertical channel with twosensor optical probe; meanwhile, it is found that void fraction profiles in the experiment are concave profile, convex profile, and two-peak profile. Sun [15] reported the radial distributions of local void fraction and bubble frequency in the low-mass flux subcooled flow boiling. For vertical 


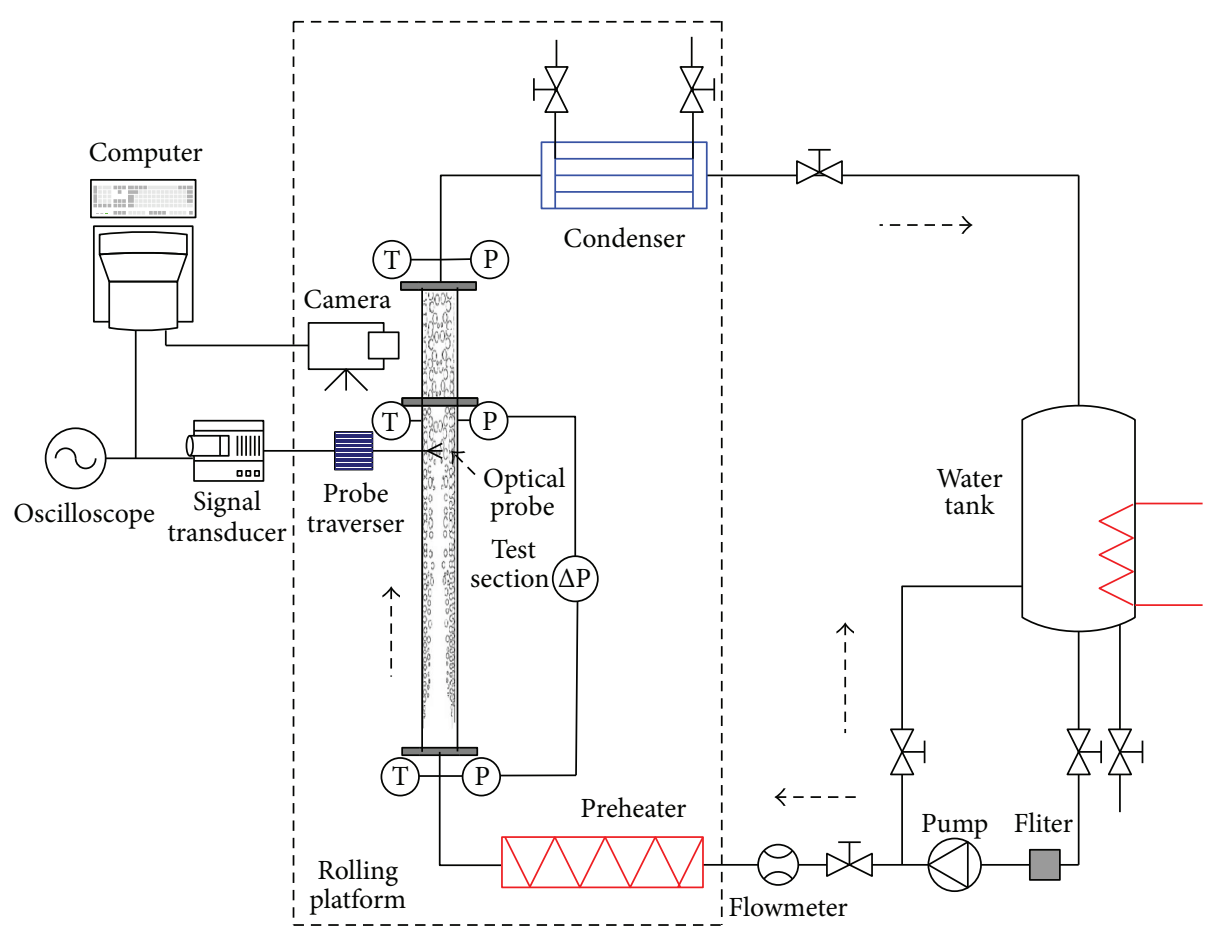

Figure 1: Schematic diagram of test loop.

annulus channel, Hasan et al. [16] and Roy and Velidandla [17] measured local void fraction, gas velocity, and bubble diameter in R-113 boiling flow. Recently, it has been presented in the studies of Situ et al. [18], Lee et al. [19], and Yun et al. [20] that local measurements of void fraction, bubble diameter, interfacial velocity, and liquid velocity in subcooled flow boiling were performed in annulus channel. Besides, some double-sensor conductivity probes were used for the measurements of the local interfacial parameters at three or more axial locations.

The above studies are mainly focused on the local interfacial characteristics of two-phase flow under the vertical condition. Inclined condition extensively occurred in the field of ship industry and chemical engineering. The trend of developing applications for ocean environments has attracted growing interests on two-phase flow under inclined condition. Therefore, the flow pattern, void fraction, and pressure drop of two-phase flow in inclined tubes have been studied extensively [21-25]. However, only very few literatures have focused on the local interfacial parameter distribution under inclined condition. Spindler and Hahne [26] have investigated the void fraction and bubble frequency profiles of adiabatic two-phase flow in an inclined tube with the method of optical fiber probe. Recently, Xing et al. [27] have researched the radial distribution of interfacial parameters for air-water bubbly flow in a circular tube under inclined condition with the double-sensor optical fiber probe. Only one-dimensional distribution of the local interfacial parameter in inclined bubbly flow has been experimentally studied in the previous task. Among all of the existing experiments measured along single direction of cross section in an inclined tube, the asymmetrical distributions of local parameters have been found in these experiments.
However, the measurement of multiple directions can fully reflect the three-dimensional distribution characteristics. It is regrettable that few studies aim at the phase distribution in different directions under inclined condition. Recently, Bao et al. [28] measured local interfacial parameters for subcooled flow boiling in an inclined circular tube. It is required not only by the profile for one chord of tube cross section but also by some profiles for other direction in the cross section, for it better gains the physical insight into the distribution characteristics of subcooled flow boiling under inclined condition. From this point of view, this experimental study aims to investigate the phase distribution of subcooled flow boiling in inclined circular tube under different directions.

\section{Material and Methods}

2.1. Experimental Loop. A schematic of the experimental loop used for this study is shown in Figure 1. The experimental system has been introduced by previous work [28]. As can be seen in Figure 1, the preheater, condenser, test section, optical probe, and probe traverser are mounted onto the rolling platform and the other apparatus are on the floor. The two parts of the test loop are connected with flexible pipe. The deionized water is stored in a tank, and the noncondensable gas in the water is removed by a heater. The water is circulated by the drive of the pump. Two regulated valves were installed separately on the bypass, and the test branch controls the flow rate through the test section. A direct electrical-heating preheater is used to regulate the liquid temperature at the inlet of the heated test section. The uniform heat flux is provided by the $80 \mathrm{~kW}$ DC power supply. Two-phase mixture flowing out of the test section is chilled by a condenser. The test section is a circular tube with 
an inner diameter of $24 \mathrm{~mm}$ and a heated length of $1000 \mathrm{~mm}$. There are two parts in this section. One is the heated section made of stainless steel, and the other one is the visual section made of quartz glass.

The volumetric flow rate was measured with a venturi flowmeter and the accuracy of flow measurement was $\pm 2 \%$ of the full-scale flow. Two test gauges with accuracy of $\pm 0.1 \%$ were installed to measure the pressure at the inlet and outlet of the test section. The pressure drop across the inlet and outlet of the heated section was measured with the pressure differential pressure transmitters of range $0 \sim 0.2 \mathrm{MPa}$ with accuracy of $\pm 0.1 \%$ of full-scale pressure drop. Some N-type thermocouples were used to measure fluid temperatures at the inlet and outlet of the heated test section. A typical uncertainty associated with temperature measurement was $\pm 1^{\circ} \mathrm{C}$. The heat flux to the heated test section was obtained by measuring the current into the test section and the voltage drop across the heater. The electrical current was measured using a digital multimeter, and the voltage was measured using a multirange voltmeter. Maximum uncertainty in power measurement was $\pm 1 \%$ of measured power. The heat loss to the ambient is estimated from the sensible heat that is gained by the fluid for singlephase heat transfer conditions.

2.2. Optical Probe System. To quantify the complicated local interfacial characteristic in subcooled flow boiling, a double-sensor optical fiber probe was applied to measure the local interfacial parameters. A signal processor generated high- or low-voltage signal corresponding to the vapor and liquid phases around the probe tip, with each pulse representing a bubble hitting the sensor tip. The doublesensor probe consists of two independent sensors, the two sensor tips space $0.7 \mathrm{~mm}$ along the main flow direction and upstream one is called the front sensor. The location of the optical probe was at axial position of $40 D(D=24 \mathrm{~mm})$ distance from the entrance. The optical probe can move with the drive of a probe traverse with $0.02 \mathrm{~mm}$ resolution. For inclined condition, the probe was traversed in $r / R=-0.95 \sim 0.95$ to obtain the radial profiles of local parameters; $r$ and $R$ are the radial distance from the center and the inner radius of the heated tube, respectively.

Based on the signal from the two-sensor probe, local void fraction and bubble frequency are calculated by the signals of the front sensor. Local void fraction is equal to the ratio of all of the bubble-dwelling time measured by the front sensor to the total sampling time (T), which can be expressed by

$$
\alpha=\frac{\sum\left(t_{j}-t_{j-1}\right)}{T}=\frac{\sum \Delta t_{j}}{T} .
$$

Local bubble frequency is equal to the ratio of the bubble numbers $(N)$ passing through the front fiber tip in the measurement time to the total sampling time,

$$
f_{\mathrm{b}}=\frac{N}{T}
$$

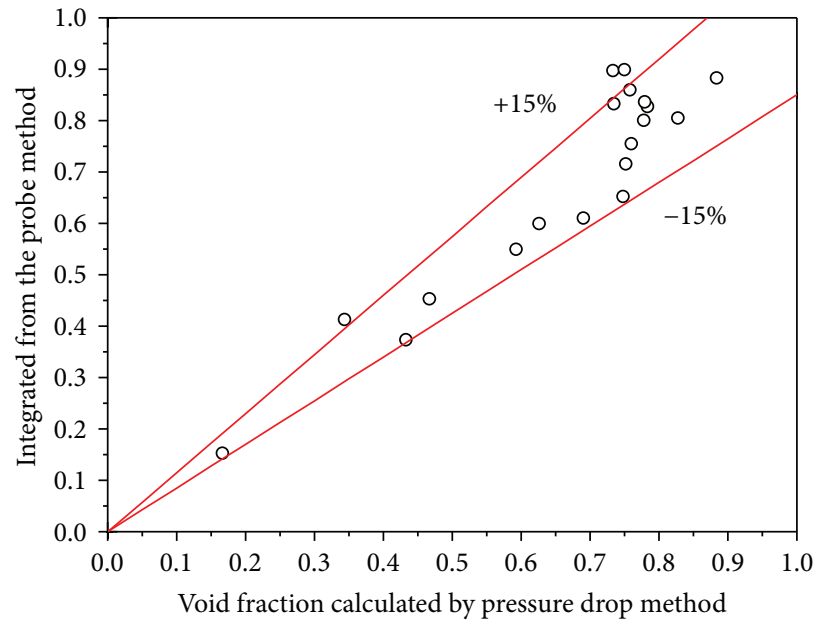

(a)

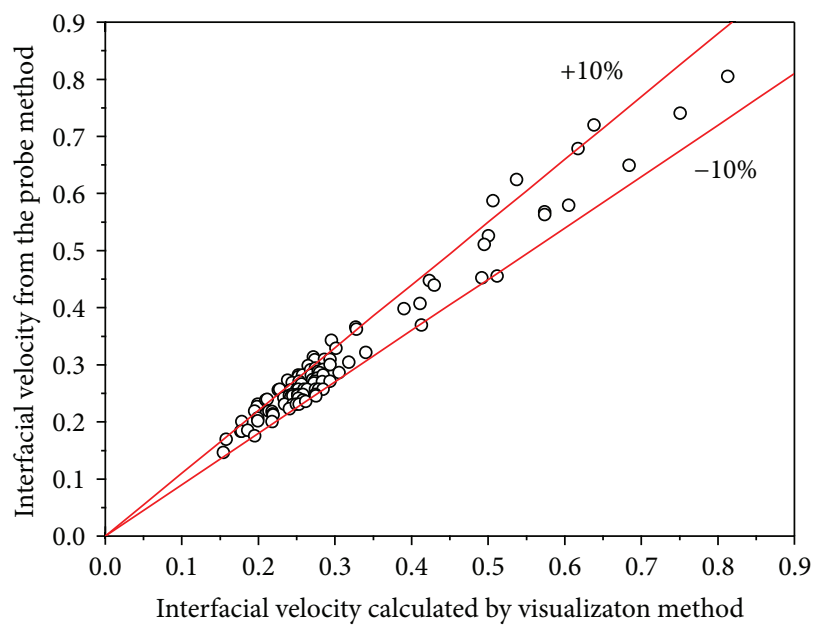

(b)

FIGURE 2: Uncertainty of the two-sensor optical probe: (a) void fraction; (b) interfacial velocity.

The interfacial velocity parallel to the flow direction can be simply calculated from the distance between the two sensor tips and the time difference, and it can be expressed as

$$
v_{\mathrm{i}}=\frac{\Delta s}{\Delta t_{\mathrm{kl}}} .
$$

Local IAC calculated by the method of Wu and Ishii [29], who considered the effect of bubble lateral motions on the IAC measured,

$$
\alpha_{\mathrm{i}}=\frac{2 N_{\mathrm{b}}}{\Delta s \Delta T}\left[2+\left(\frac{v_{\mathrm{b}}^{\prime}}{v_{\mathrm{b}}}\right)^{2.25}\right] \frac{\sum_{j}\left(\Delta t_{j}\right)}{N_{\mathrm{b}}-N_{\mathrm{miss}}} .
$$

$\Delta T, N_{\mathrm{b}}, N_{\text {miss }}$, and $\nu_{\mathrm{b}}^{\prime} / \nu_{\mathrm{b}}$ denote the sampling time, the total numbers detected by the front sensor, the number of the missed bubbles, and the relative bubble velocity fluctuation, respectively. The missed bubbles referred to those are touched by the front sensor but not by the rear sensor, or those pass the rear sensor ahead of the front sensor due to 


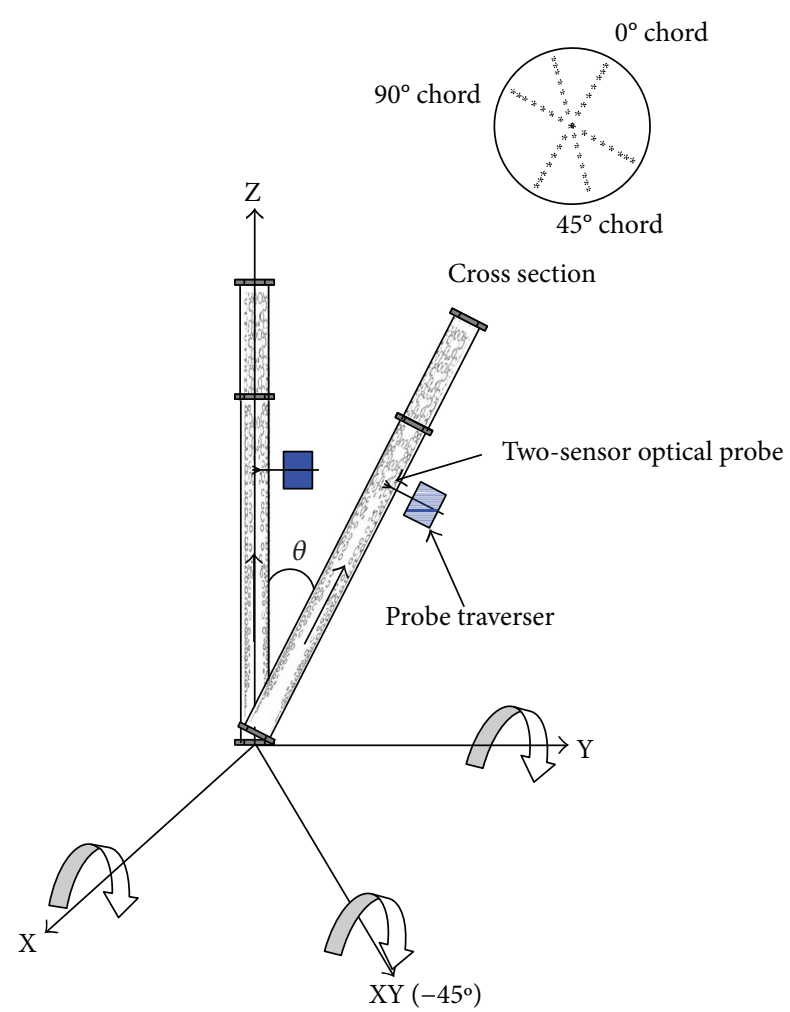

Figure 3: Diagram of test section under vertical and inclined condition.

bubble lateral motions. They also reported the relative bubble velocity fluctuation.

It can be seen from Figure 2 that the probe measurement results show good agreement with the void faction calculated by pressure drop method, and the maximum relative error is less than $15 \%$. It is also found that the maximum relative error between the local interfacial velocities measured by probe and that by the visualization method is less than $10 \%$.

2.3. Experimental Methods. The measurement method named multiangle between the direction of motion and the measuring is used in the experiment, which can obtain the local interfacial parameters in different directions of the inclined tube cross section. As shown in Figure 3, the inclination angle can be adjusted between $\theta=0^{\circ}$ (vertical) and $\theta=30^{\circ}$; in addition, the test tube can incline through different directions with the help of the moveable platform. As a result, according to the angle between the two directions of inclination axis and probe measurement, three chords $\left(0^{\circ}, 45^{\circ}\right.$, and $90^{\circ}$ chord) of different directions in the tube cross section can be measured under the inclined condition. $\beta=90^{\circ}$ means that the measuring direction is perpendicular to the inclination axis direction, and $\beta=0^{\circ}$ means that the measuring direction is parallel to the inclination axis direction; $r=0$ corresponds to the channel center, whereas $r / R>0$ and $r / R<0$ represent the lower and upper half part of inclined cross section of tube, respectively.

Figure 4 shows the measurement repeatability of the two-sensor probe at $r / R=0$ for the three chords in the

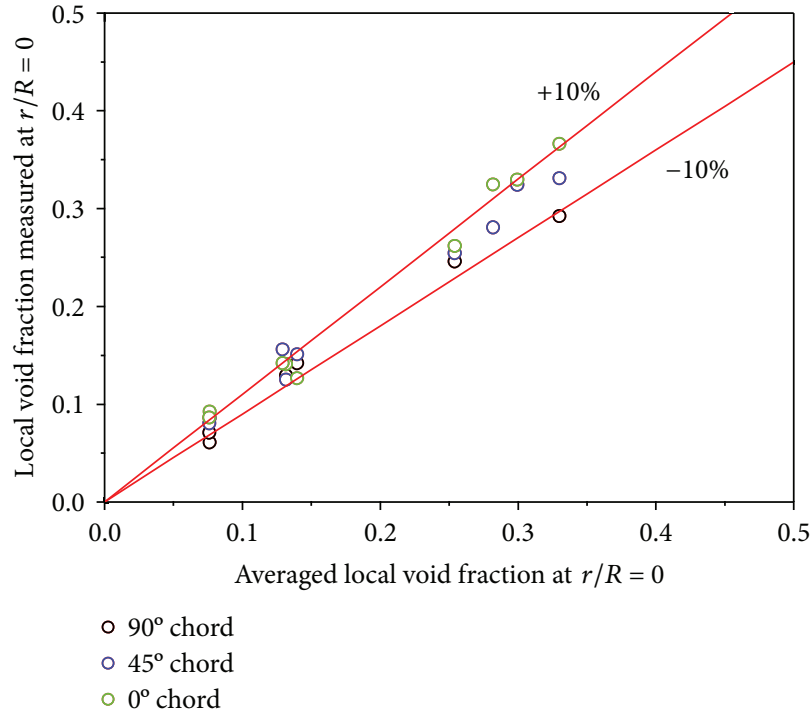

(a)

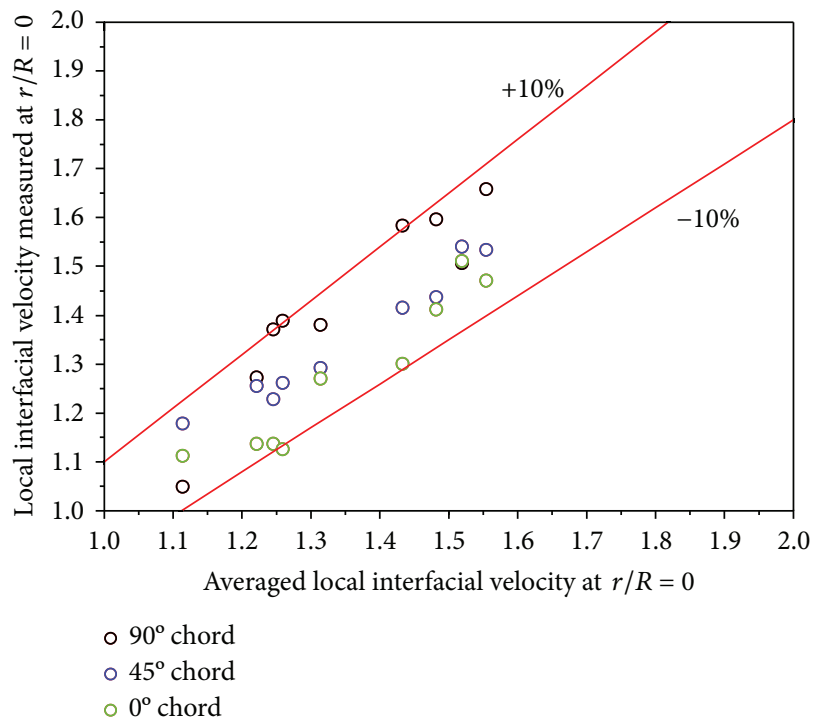

(b)

Figure 4: Repeatability of the two-sensor optical probe measurement at $r / R=0$ : (a) void fraction; (b) interfacial velocity.

tube cross section. It has also been found that the local void fraction and local interfacial velocity are similar regardless of the measurement chord when the tube inclined for any axis. To sum up, it clearly indicates that the multiangle measurement method is reasonable.

\section{Results and Discussion}

3.1. The Characteristics of Phase Distribution for Subcooled Flow Boiling under the Inclined Condition. Figure 5 clearly shows the characteristics of the phase distributions of subcooled flow boiling under inclined condition. As presented in the figures, local void distribution for inclined condition is quite different from that for vertical condition, and the phase distribution profiles are not symmetrical in inclined tube. Moreover, the different distribution profiles occurred 


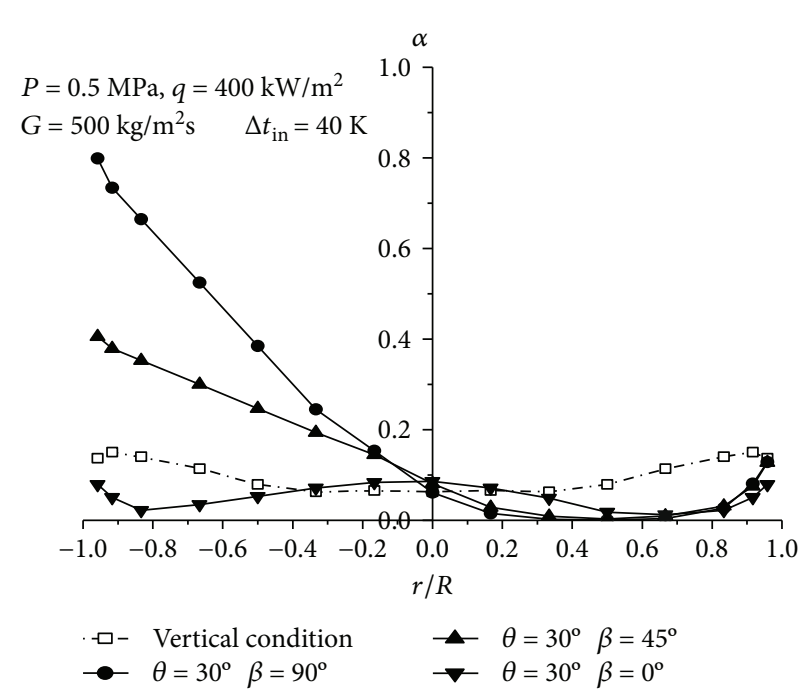

(a) Local void fraction

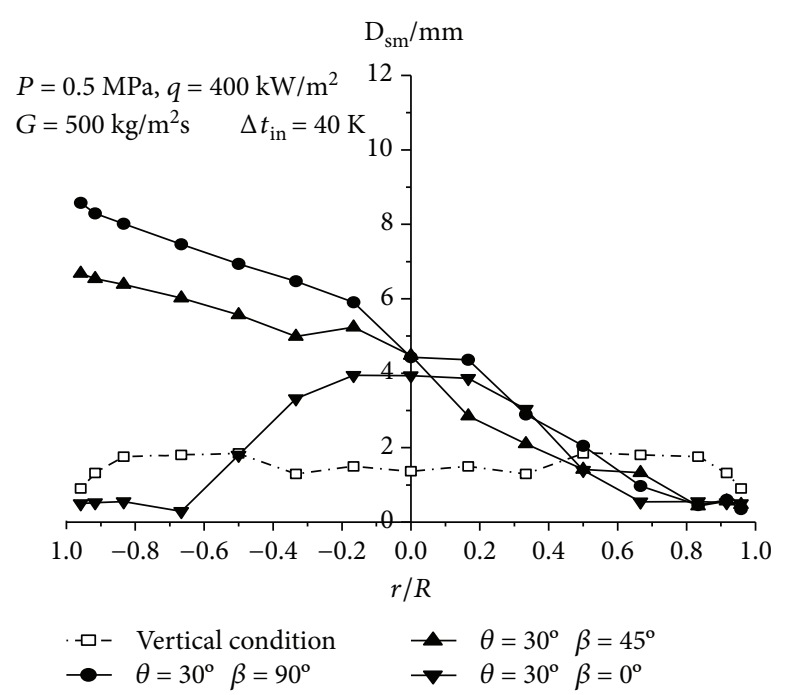

(b) Bubble Sauter diameter

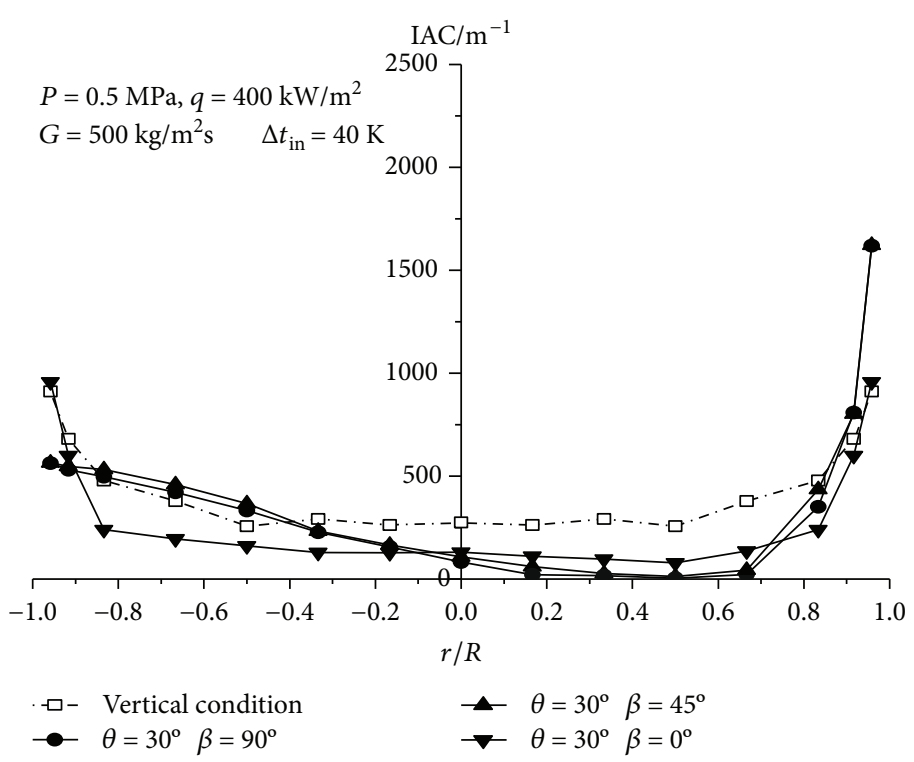

(c) Interfacial area concentration

Figure 5: Phase distribution of subcooled flow boiling under inclined condition.

in three measured directions. That is to say, the profile of local interfacial parameters highly skewed at $90^{\circ}$ chord and $45^{\circ}$ chord, while the profile is still symmetrical at $0^{\circ}$ chord. These results can be explained by the fact that buoyancy caused the bubbles to move toward the upper side of inclined tube and congregate. Owing to the lateral migration and polymerization of bubbles onto the upper wall of the channel, the peak value of the local void fraction appears in the $r / R=-1$ position of the inclined channel; in addition, the largest bubble Sauter diameter appears in this position as well. Because of the increase of the bubble size, the IAC is smaller than that under the static condition, which indicates that the heat transfer ability between the liquid and vapour phase at the top of the inclined channel becomes weaker. As the bubbles emerge from the heated wall, there are still some bubbles at the bottom of the inclined channel $(r / R=1)$. As we can see in the picture, the local void fraction and bubble size at the bottom of the flow path are less affected by the inclination. Meanwhile, due to the migration of large bubbles to the top of the tube, the IAC can be larger than that under static condition, which indicates that the heat transfer between the liquid and vapour phase at the bottom of the inclined channel is becoming stronger.

3.2. The Influence of the Inclination Angle on the Phase Distribution for Subcooled Flow Boiling. According to the analysis above, the phase distribution on the direction of $\beta=90^{\circ}$ and $\beta=45^{\circ}$ is similar, and the phase distribution on the direction of $\beta=0^{\circ}$ is still symmetrical. As follows, the analysis of phase distribution characteristics on the directions of $\beta=90^{\circ}$ and $\beta=0^{\circ}$ has been conducted, respectively.

3.2.1. The Characteristics of the Phase Distribution on the Direction of $\beta=90^{\circ}$ in Cross Section. Figures 6-8 shows the 


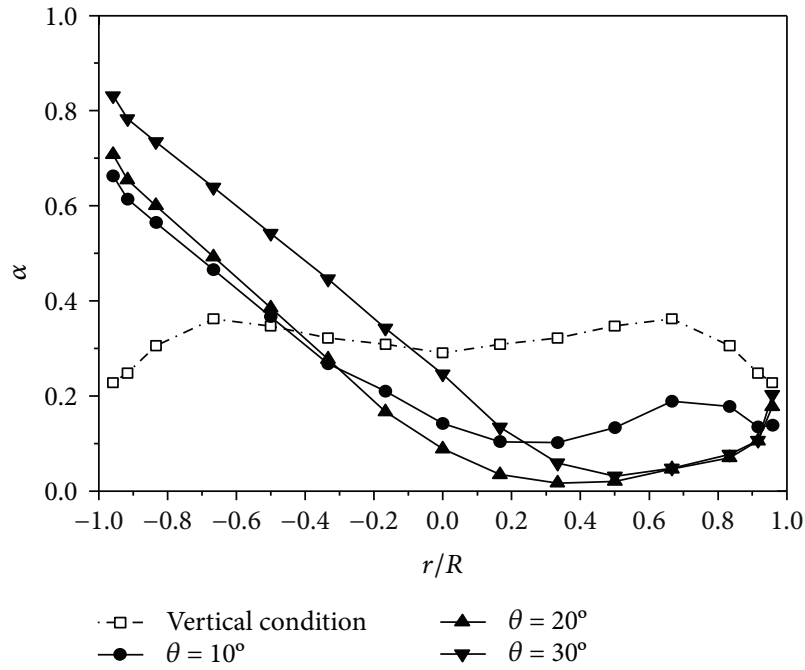

(a) $q=400 \mathrm{~kW} / \mathrm{m}^{2}$

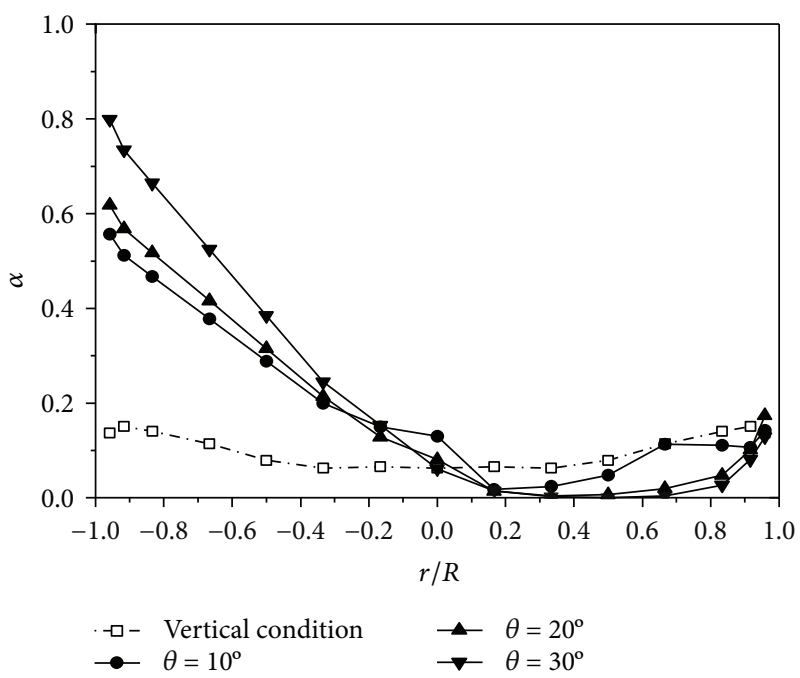

(b) $q=450 \mathrm{~kW} / \mathrm{m}^{2}$

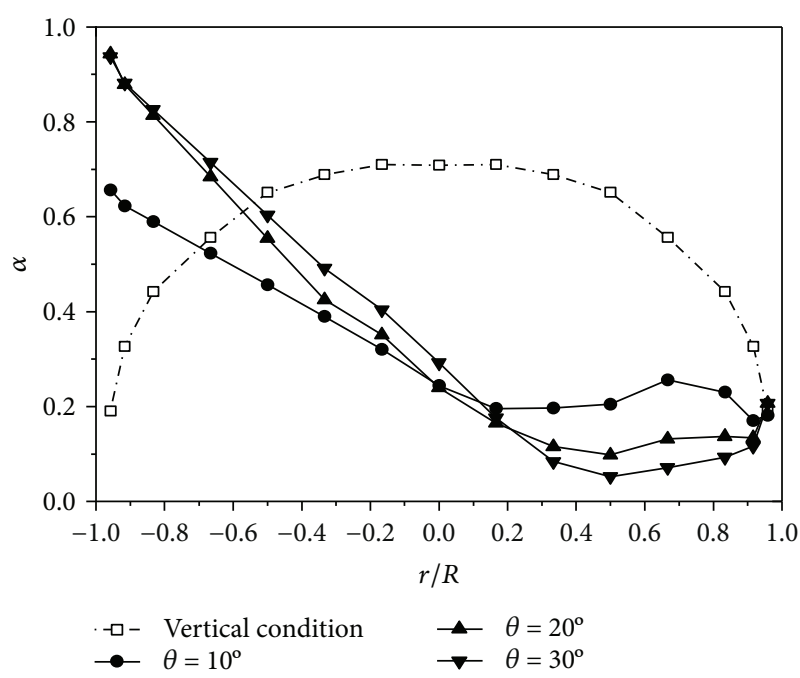

(c) $q=500 \mathrm{~kW} / \mathrm{m}^{2}$

FIGURE 6: Inclination angle effect on the local void fraction on the direction of $\beta=90^{\circ}$ in cross section $\left(P=0.5 \mathrm{MPa}, G=500 \mathrm{~kg} / \mathrm{m}^{2} \mathrm{~s}\right)$.

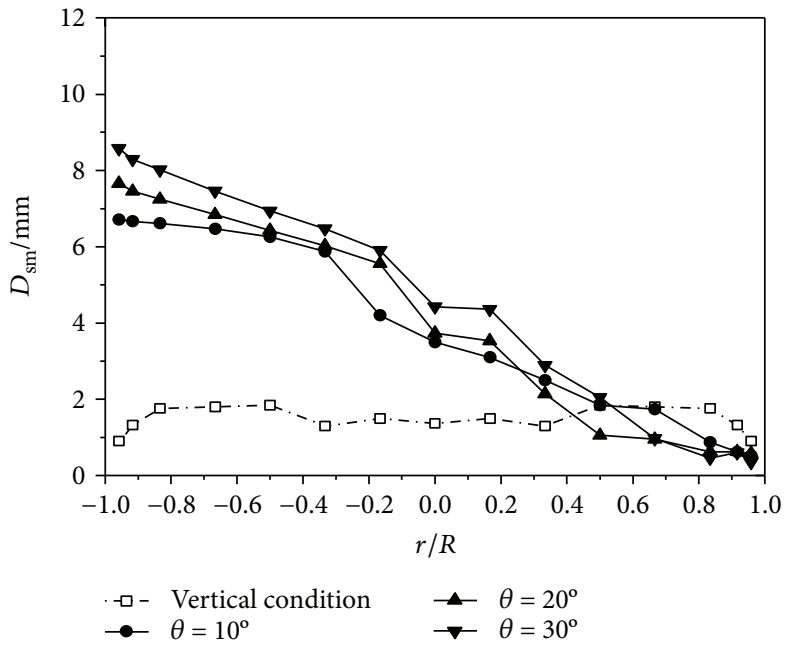

(a) $q=400 \mathrm{~kW} / \mathrm{m}^{2}$

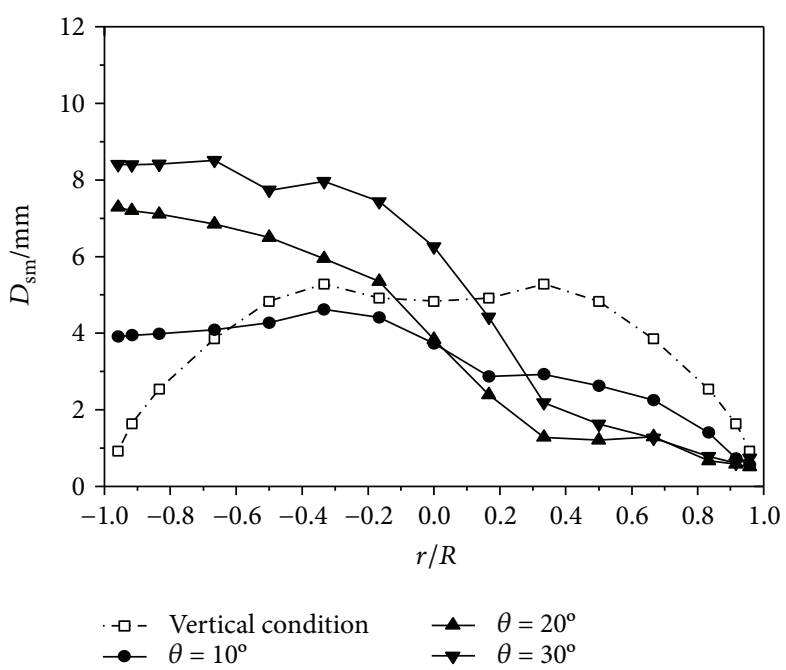

(b) $q=450 \mathrm{~kW} / \mathrm{m}^{2}$

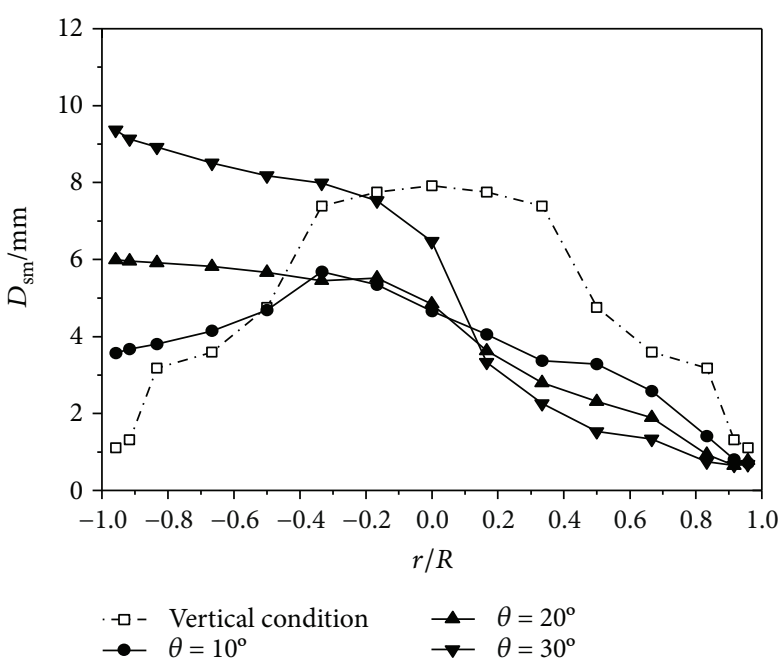

(c) $q=500 \mathrm{~kW} / \mathrm{m}^{2}$

Figure 7: Inclination angle effect on the bubble Sauter diameter on the direction of $\beta=90^{\circ}$ in cross section $(P=0.5 \mathrm{MPa}$, $G=500 \mathrm{~kg} / \mathrm{m}^{2} \mathrm{~s}$ ). 


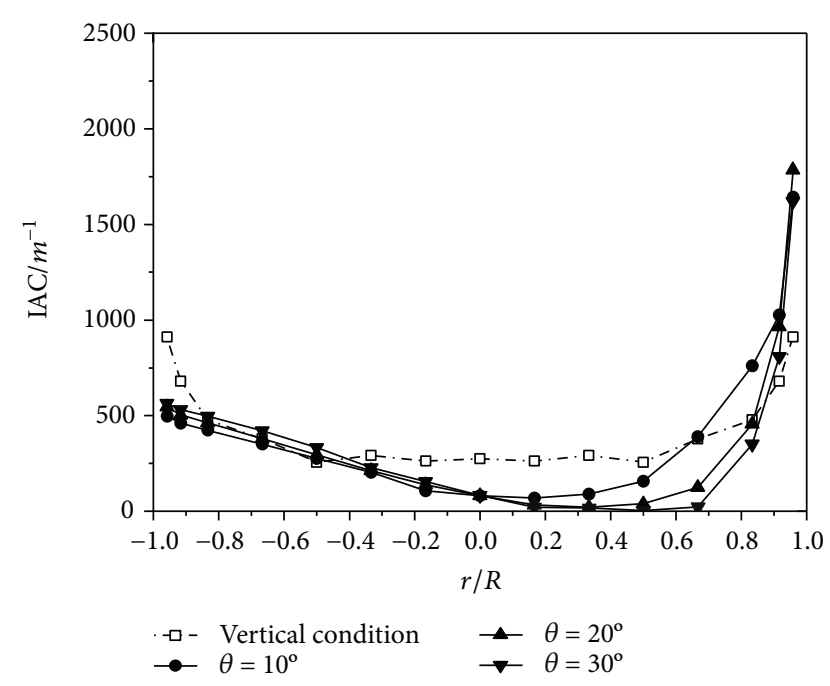

(a) $q=400 \mathrm{~kW} / \mathrm{m}^{2}$
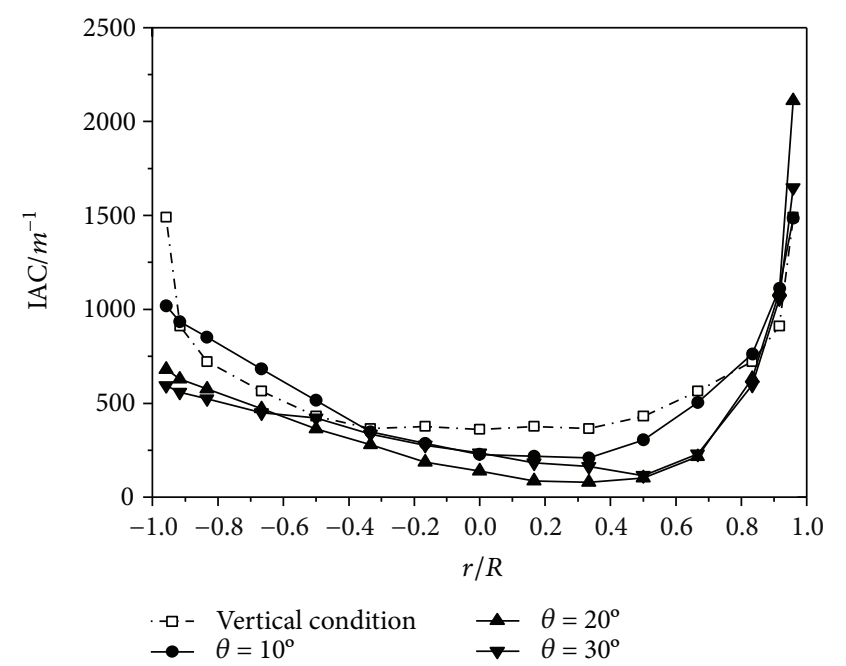

(b) $q=450 \mathrm{~kW} / \mathrm{m}^{2}$

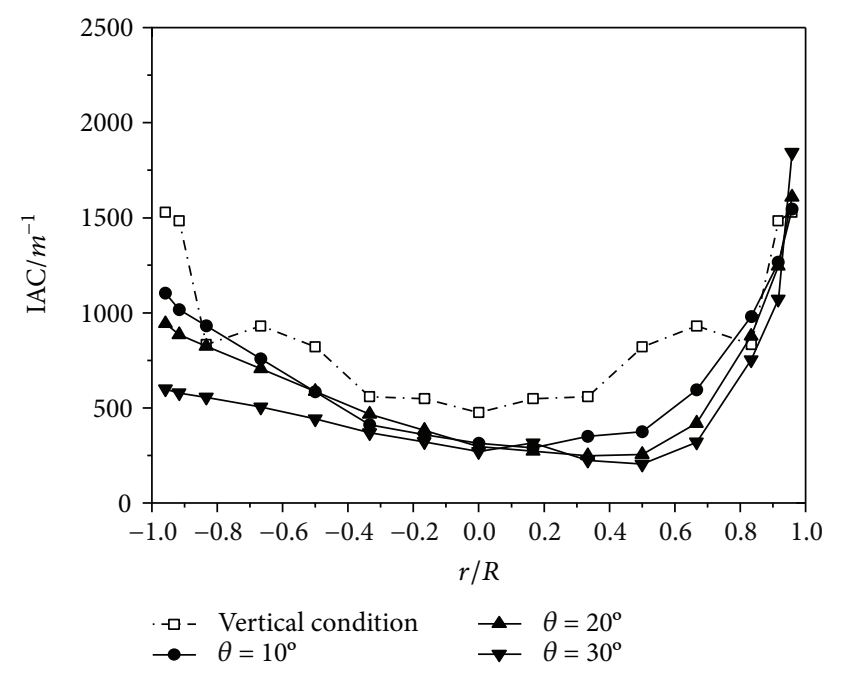

(c) $q=500 \mathrm{~kW} / \mathrm{m}^{2}$

Figure 8: Inclination angle effect on the interfacial area concentration on the direction of $\beta=90^{\circ}$ in cross section $\left(P=0.5 \mathrm{MPa}, G=500 \mathrm{~kg} / \mathrm{m}^{2} \mathrm{~s}\right)$. influence of the inclination angle on the deviation of local void fraction, bubble size, and IAC on the direction of $\beta=$ $90^{\circ}$. As we can see, with the increasing of the inclination angle, deviation of local void fraction, bubble size, and IAC, the peak value of local void fraction increases on the top of tube; meanwhile, the bubble Sauter diameter of also raises but IAC decreases slightly. This can be explained by the reason that the radial part of buoyancy increases with the rising of the inclination angle. Hence, it results in more bubble aggregation on the top of the flow channel and the uneven phase distribution of the subcooled flow boiling under inclined condition exacerbates.

It can be seen in Figure 6 that the peak value near the location where $r / R=-1$ increases as the inclination angle increases, while it becomes weakened near the $\mathrm{r} / \mathrm{R}=0.8$ and the inclination angles will affect the typical distributions in some degree. When heat flux $q=400 \mathrm{~kW} / \mathrm{m}^{2}$, the local void core peak profile changes into intermediate peak profile as the inclination angle increases at the lower half part of the inclined tube. Even in the case of $30^{\circ}$ for an inclination angle, the peak near the lower side will disappear, when the heat flux is lower and the wall peak profile occurred. It is also found that local void fraction at $r / R=-1$ was independent of the inclination angle. The reason is the bubble generation controlled by the heat surface in subcooled flow boiling.

The local bubble Sauter diameter profile is illustrated in Figure 7. As clearly reported in some literature, the lift force pushes the small bubbles toward the wall in vertical upward flow, while the direction of lift force is reversed when the bubble diameter exceeds the threshold size. Different from vertical flow, the buoyancy force has a radial component normal to the tube axis. For large size bubbles, the direction of force is the same as the lift force in the lower part of the tube while it reverses to the lift force in the upper part of the tube. Therefore, large bubbles moved to the upper part of the tube and congregate. For small size bubbles, more of them moved to the upside resulting from the direction of $\mathrm{F}$ which reversed to the lift force in the lower part of tube.

Figure 8 shows typical profiles of the measured local IAC; there is an approximately symmetrical profile for inclined condition. Local IAC explicitly decreased near the upper side at $90^{\circ}$ direction when heat flux was high when compared with that for vertical condition. This explains that IAC is proportional to void fraction, but inversely proportional to bubble size. And it causes the decrease of IAC in this region with the aforementioned bubbles near the upper side of the inclined tube becoming larger.

3.2.2. The Characteristics of the Phase Distribution on the Direction of $\beta=0^{\circ}$ in Cross Section. Figure 9-11 shows the influence of the inclination angle on the local void fraction, bubble size, and IAC on the direction of $\beta=0^{\circ}$ in the flow channel. It can be clearly seen that the profile of phase distribution still maintains symmetrical. In addition, the influence of the inclination angle on the phase distribution in this direction is also of vital significance. 


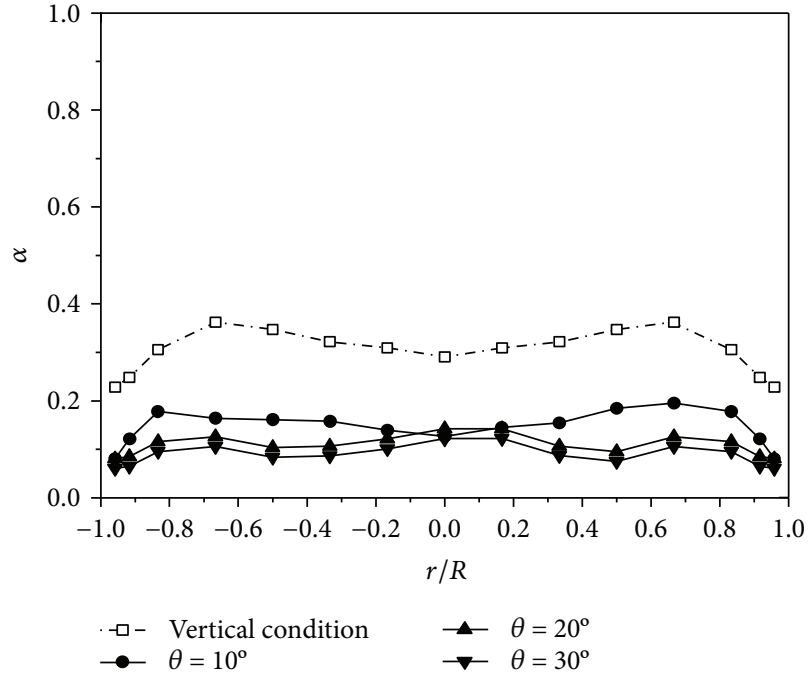

(a) $q=400 \mathrm{~kW} / \mathrm{m}^{2}$

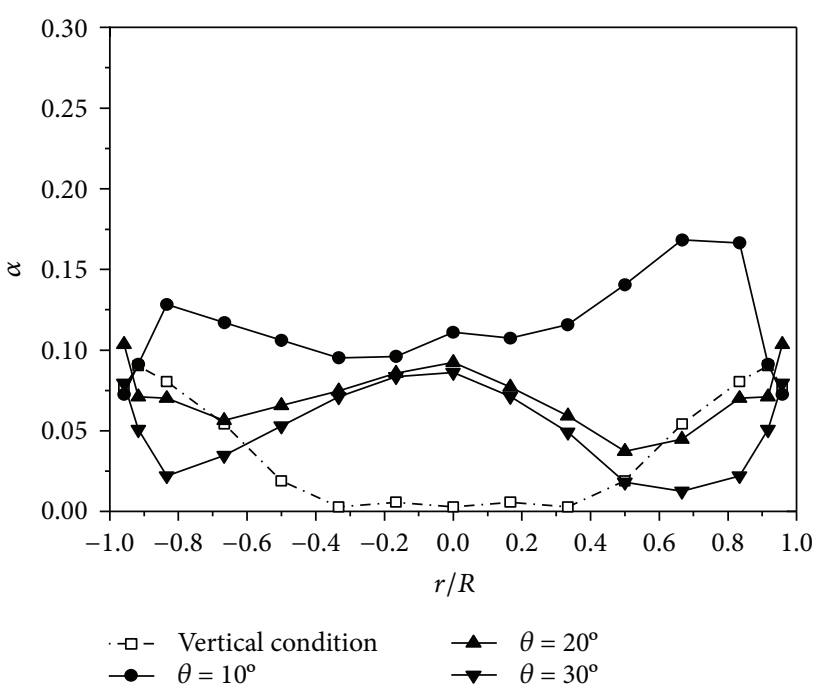

(b) $q=450 \mathrm{~kW} / \mathrm{m}^{2}$

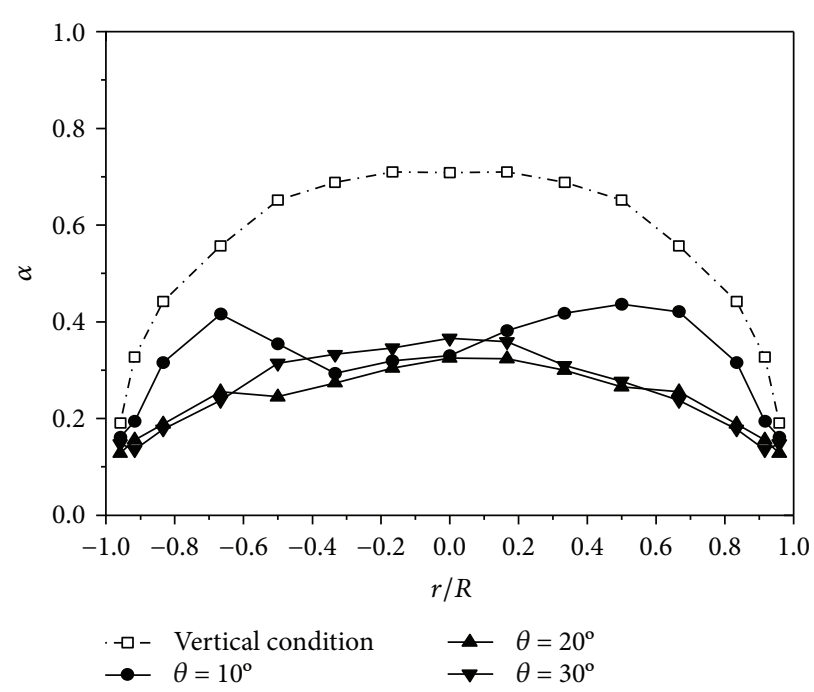

(c) $q=500 \mathrm{~kW} / \mathrm{m}^{2}$

FIGURE 9: Inclination angle effect on the local void fraction on the direction of $\beta=0^{\circ}$ in cross section $\left(P=0.5 \mathrm{MPa}, G=500 \mathrm{~kg} / \mathrm{m}^{2} \mathrm{~s}\right)$.

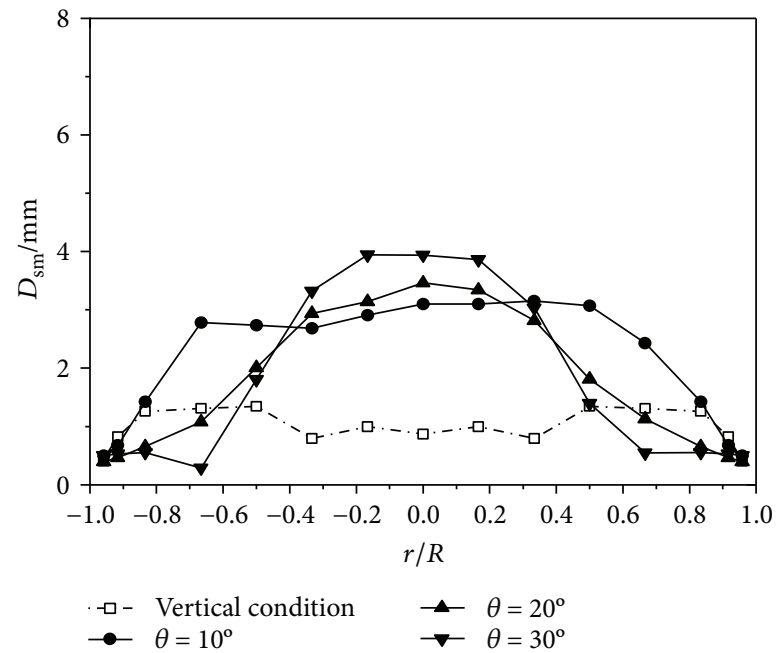

(a) $q=400 \mathrm{~kW} / \mathrm{m}^{2}$

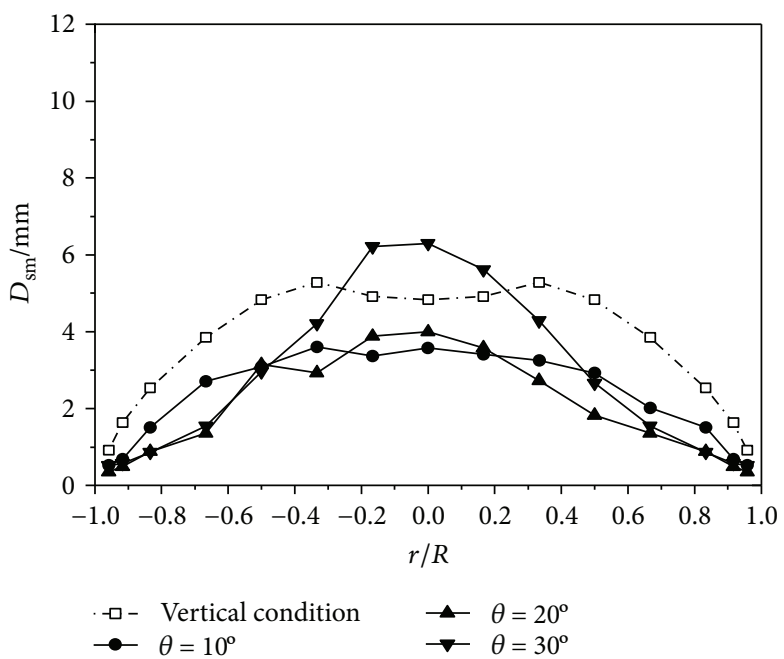

(b) $q=450 \mathrm{~kW} / \mathrm{m}^{2}$

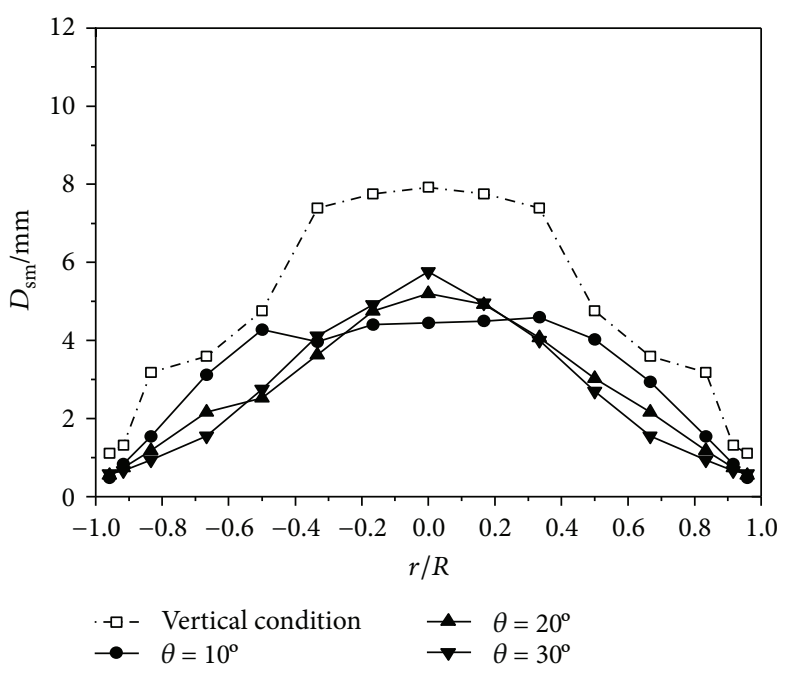

(c) $q=500 \mathrm{~kW} / \mathrm{m}^{2}$

FIgURE 10: Inclination angle effect on the bubble Sauter diameter on the direction of $\beta=0^{\circ}$ in cross section $(P=0.5 \mathrm{MPa}$, $G=500 \mathrm{~kg} / \mathrm{m}^{2} \mathrm{~s}$ ) 


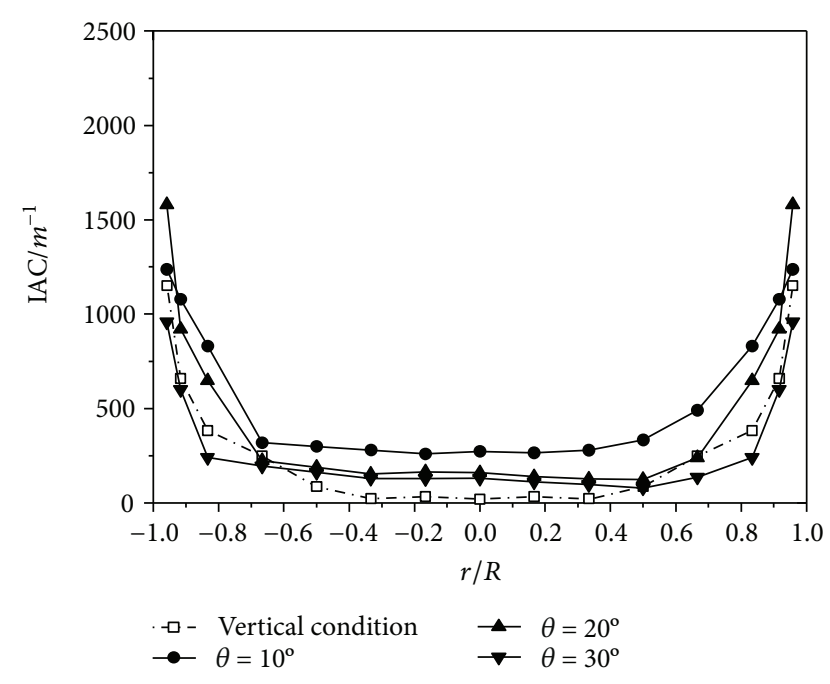

(a) $q=400 \mathrm{~kW} / \mathrm{m}^{2}$

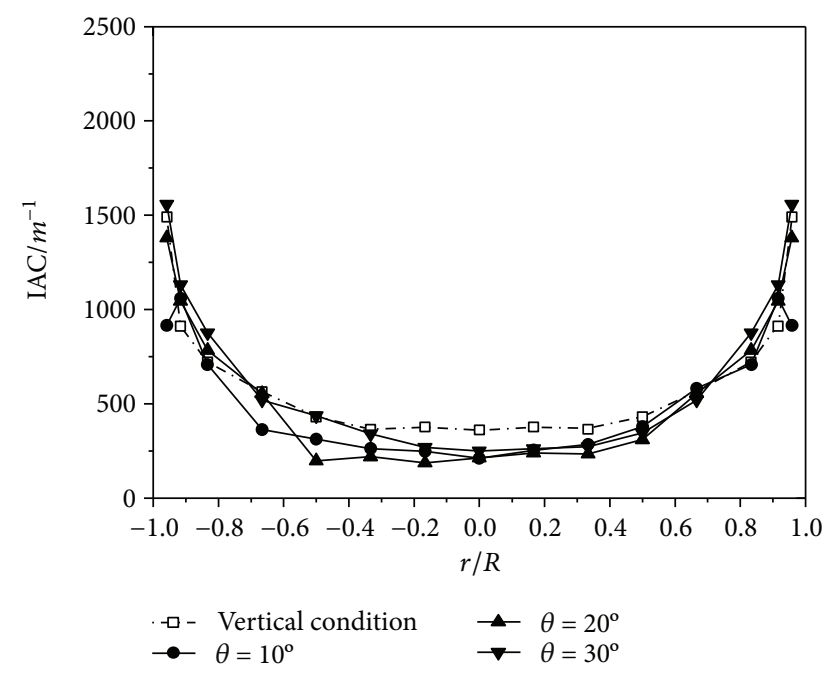

(b) $q=450 \mathrm{~kW} / \mathrm{m}^{2}$



(c) $q=500 \mathrm{~kW} / \mathrm{m}^{2}$

Figure 11: Inclination angle effect on the interfacial area concentration on the direction of $\beta=0^{\circ}$ in cross section $\left(P=0.5 \mathrm{MPa}, G=500 \mathrm{~kg} / \mathrm{m}^{2} \mathrm{~s}\right)$.
Figure 9 shows the local void fraction distribution under different inclination angles. When the heat flux is $q=400 \mathrm{~kW} / \mathrm{m}^{2}$, the bubbles rise along the radial direction under inclined condition. With the increase of the inclination angles, the near-wall peak gradually disappeared. Meanwhile, the local void fraction in the channel center is larger than that under the condition of vertical. As the heat flux increases, the local void fraction distribution on the direction of $\beta=0^{\circ}$ is more uneven. From Figure 10, it can be seen that the size of the bubble in the inclined channel is mainly the core-peak distribution. The inclination angle has little influence on the size of the bubble near the wall. With the increase of the inclination angle, the bubble size increases as well. Figure 11 shows that the inclination angle has little influence on the IAC on the direction of $\beta=0^{\circ}$ due to the reason that more large bubbles occur and gather onto the top of tube when the heat flux increases.

\section{Conclusions}

In this paper, local interfacial characteristics in subcooled flow boiling were investigated under vertical and inclined conditions. For vertical upward subcooled flow boilings, the local interfacial parameters presented three kinds of distribution types, including wall peak, core peak, and intermediate peak. As it is expected, the phase distribution under the inclined condition is different from the phase distribution under the vertical condition. The profiles skewed highly for $90^{\circ}$ and $45^{\circ}$ chord of tube cross section, whereas the profile was also symmetrical at $0^{\circ}$ chord. These results can be explained by the fact that buoyancy caused the bubbles to move toward the top of the tube cross section under inclined condition. In addition, the typical distributions were also influenced by the inclination angles.

\section{Nomenclature}

$a_{\mathrm{i}}: \quad$ Local interfacial area concentration $(1 / \mathrm{m})$

$D$ : Tube diameter $(\mathrm{mm})$

$D_{\text {sm }}$ : Local bubble Sauter mean diameter $(\mathrm{mm})$

$f_{\mathrm{b}}: \quad$ Local bubble frequency $(\mathrm{Hz})$

$F_{\mathrm{bl}}$ : Radial component for buoyancy force

G: $\quad$ Mass flux $\left(\mathrm{kg} / \mathrm{m}^{2} \mathrm{~s}\right)$

$N_{\mathrm{b}}$ : Bubble number of sampling

$N_{\text {miss }}$ : Missed bubble number of sampling

$P: \quad$ Pressure $(\mathrm{MPa})$

$q$ : Heat flux $\left(\mathrm{kW} / \mathrm{m}^{2} \mathrm{~s}\right)$

$R: \quad$ Tube radius ( $\mathrm{mm}$ )

$r$ : Radial position for probe measurement ( $\mathrm{mm}$ )

$v_{\mathrm{i}}: \quad$ Local interfacial velocity $(\mathrm{m} / \mathrm{s})$

$\triangle T: \quad$ Samplimg time $(\mathrm{s}) /$ subcooling $\operatorname{degree}\left({ }^{\circ} \mathrm{C}\right)$.

Greek Symbols

$\alpha: \quad$ Local void fraction

$\Delta s: \quad$ Distance between two sensor tips (m)

$\Delta t_{j}: \quad$ Time delay for $i$ th interface (s)

$\Delta t_{\mathrm{kl}}$ : Time delay between the front and rear sensor (s)

$\Delta T_{\text {in }}:$ Inlet temperature. 


\section{Conflicts of Interest}

The authors declare that they have no conflicts of interest.

\section{Acknowledgments}

This work is supported by the National Natural Science Foundation of China under Grant nos. 11475161 and 11505176.

\section{References}

[1] M. Higuchi and T. Saito, "Quantitative characterizations of long-period fluctuations in a large-diameter bubble column based on point-wise void fraction measurements," Chemical Engineering Journal, vol. 160, no. 1, pp. 284-292, 2010.

[2] S. L. Kiambi, H. K. Kiriamiti, and A. Kumar, "Characterization of two phase flows in chemical engineering reactors," Flow Measurement and Instrumentation, vol. 22, no. 4, pp. 265$271,2011$.

[3] T. Hibiki and M. Ishii, "Interfacial area concentration of bubbly flow systems," Chemical Engineering Science, vol. 57, no. 18, pp. 3967-3977, 2002.

[4] K. Sun, M. Zhang, and X. Chen, "Local measurement of gasliquid bubbly flow with a double-sensor probe," Chinese Journal of Chemical Engineering, vol. 8, pp. 33-40, 2000.

[5] X. Shen and K. Mishima, "Two-phase phase distribution in a vertical large diameter pipe," International Journal of Heat and Mass Transfer, vol. 48, no. 1, pp. 211-225, 2005.

[6] X. Shen, Y. Saito, K. Mishima, and H. Nakamura, "A study on the characteristics of upward air-water two-phase flow in a large diameter pipe," Experimental Thermal and Fluid Science, vol. 31, no. 1, pp. 21-36, 2006.

[7] S. Kim, M. Ishii, Q. Wu, D. McCreary, and S. G. Beus, "Interfacial structures of confined air-water two-phase bubbly flow," Experimental Thermal and Fluid Science, vol. 26, no. 5, pp. 461-472, 2002.

[8] X. D. Sun, T. R. Smith, S. Kim, M. Ishii, and J. Uhle, "Interfacial area of bubbly flow in a relatively large diameter pipe," Experimental Thermal and Fluid Science, vol. 27, no. 1, pp. 97-109, 2002.

[9] S. T. Revankar and M. Ishii, "Local interfacial area measurement in bubbly flow," International Journal of Heat and Mass Transfer, vol. 35, no. 4, pp. 913-925, 1992.

[10] T. Hibiki and M. Ishii, "Experimental study on interfacial area transport in bubbly two-phase flows," International Journal of Heat and Mass Transfer, vol. 42, no. 16, pp. 3019-3035, 1999.

[11] T. Hibiki, M. Ishii, and Z. Xiao, "Axial interfacial area transport of vertical bubbly flows," International Journal of Heat and Mass Transfer, vol. 44, no. 10, pp. 1869-1888, 2001.

[12] X. Z. Shen, R. Matsui, K. Mishima, and H. Nakamura, "Distribution parameter and drift velocity for two-phase flow in a large diameter pipe," Nuclear Engineering and Design, vol. 240, no. 12, pp. 3991-4000, 2010.

[13] K. Sekoguchi, H. Fukui, and Y. Sato, "Flow boiling in subcooled and low quality regions heat transfer and local void fraction," in Proceedings of Fifth International Heat Transfer Conference, vol. 4, pp. 180-184, Tokyo, Japan, 1974.

[14] J. Garnier, E. Manon, and G. Cubizolles, "Local measurements on flow boiling of refrigerant 12 in a vertical tube," Multiphase Science and Technology, vol. 13, no. 1-2, p. 111, 2001.
[15] Q. Sun, Phase Distribution for Low Mass Flux Subcooled Boiling Flow [Ph. D Thesis], Tsinghua University, 2004.

[16] A. Hasan, R. P. Roy, and S. P. Kalra, "Some measurements in subcooled flow boiling of refrigerant-113," Journal of Heat Transfer, vol. 113, no. 1, p. 216, 1991.

[17] R. P. Roy and V. Velidandla, "Local measurements in the two-phase region of turbulent subcooled boiling flow," Journal of Heat Transfer, vol. 116, no. 3, p. 660, 1994.

[18] R. Situ, T. Hibiki, X. D. Sun, Y. Mi, and M. Ishii, "Axial development of subcooled boiling flow in an internally heated annulus," Experiments in Fluids, vol. 37, no. 4, pp. 589-603, 2004.

[19] T. Lee, R. Situ, T. Hibiki, H. Park, M. Ishii, and M. Mori, "Axial developments of interfacial area and void concentration profiles in subcooled boiling flow of water," International Journal of Heat and Mass Transfer, vol. 52, no. 1-2, pp. 473-487, 2009.

[20] B. J. Yun, B. U. Bae, D. J. Euh, G. C. Park, and C. H. Song, "Characteristics of the local bubble parameters of a subcooled boiling flow in an annulus," Nuclear Engineering and Design, vol. 240, no. 9, pp. 2295-2303, 2010.

[21] J. G. Jing, M. Y. Zhang, and X. J. Chen, "A study on flow pattern transitions for gas-liquid two-phase upward flow in an inclined tube," Journal of Xi'an Jiaotong University, vol. 28, pp. 143-150, 1994.

[22] S. Wongwises and M. Pipathattakul, "Flow pattern, pressure drop and void fraction of two-phase gas-liquid flow in an inclined narrow annular channel," Experimental Thermal and Fluid Science, vol. 30, no. 4, pp. 345-354, 2006.

[23] J. Y. Xu, Y. X. Wu, Z. H. Shi, L. Y. Lao, and D. H. Li, “Studies on two-phase co-current air non-Newtonian shear-thinning fluid flows in inclined smooth pipes," International Journal of Multiphase Flow, vol. 33, no. 9, pp. 948-969, 2007.

[24] V. Hernandez-Perez, Gas-Liquid Two-Phase Flow in Inclined Pipes [Ph. D Thesis], The University of Nottingham, 2008.

[25] A. Abdulahi, L. Abdulkareem, S. Sharaf, M. Abdulkadir, V. Hernandez Perez, and B. J. Azzopardi, "Investigating the effect of pipe inclination on two-phase gas-liquid flows using advanced instrumentation," in The 8th Thermal Engineering Joint Conference (AJTEC2011), Honolubu, HI, USA, March, 2011.

[26] K. Spindler and E. Hahne, "An experimental study of the void fraction distribution in adiabatic water-air two-phase flows in an inclined tube," International Journal of Thermal Sciences, vol. 38, no. 4, pp. 305-314, 1999.

[27] D. Xing, C. Yan, L. Sun, J. Liu, and B. Sun, "Experimental study of interfacial parameter distributions in upward bubbly flow under vertical and inclined conditions," Experimental Thermal and Fluid Science, vol. 47, pp. 117-125, 2013.

[28] W. Bao, B. D. Chen, J. J. Xu, T. Z. Xie, D. C. Xing, and Y. P. Huang, "Experimental study on the local interfacial characteristic of subcooled flow boiling under inclined condition," in 23rd International Conference on Nuclear Engineering, Chiba, Japan, 2015.

[29] Q. Wu and M. Ishii, "Sensitivity study on double-sensor conductivity probe for the measurement of interfacial area concentration in bubbly flow," International Journal of Multiphase Flow, vol. 25, no. 1, pp. 155-173, 1999. 

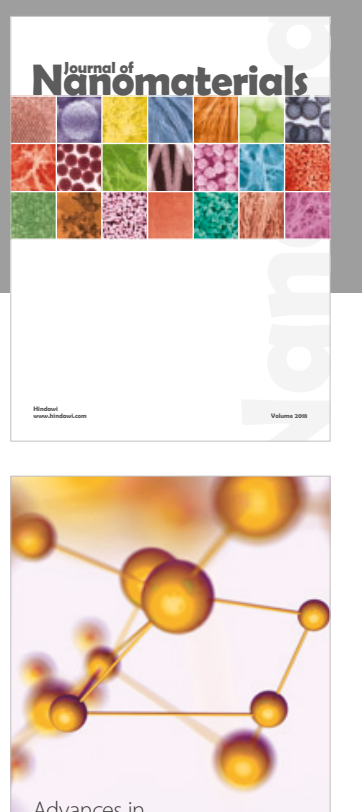

Physical Chemistry
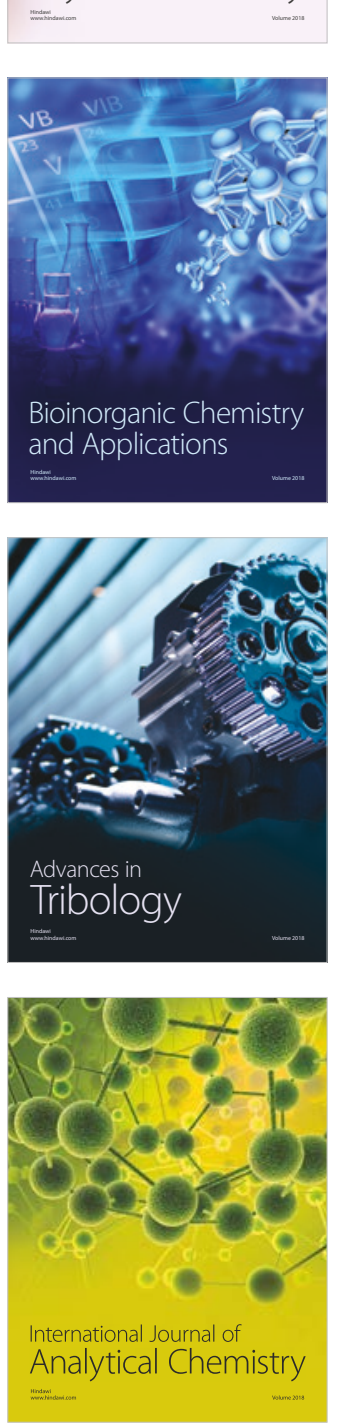

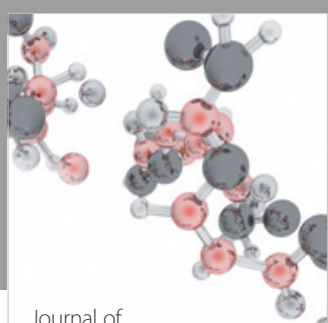

Analytical Methods

in Chemistry

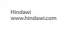

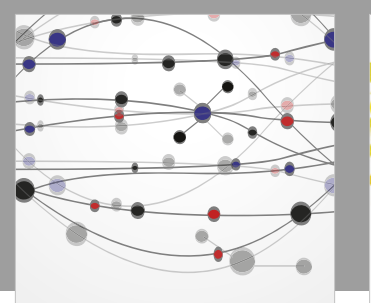

The Scientific World Journal

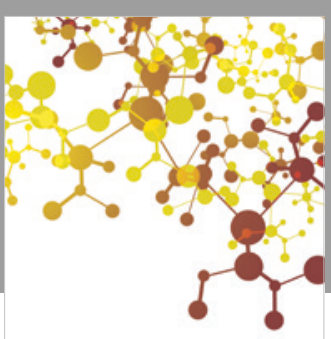

Journal of

Applied Chemistry
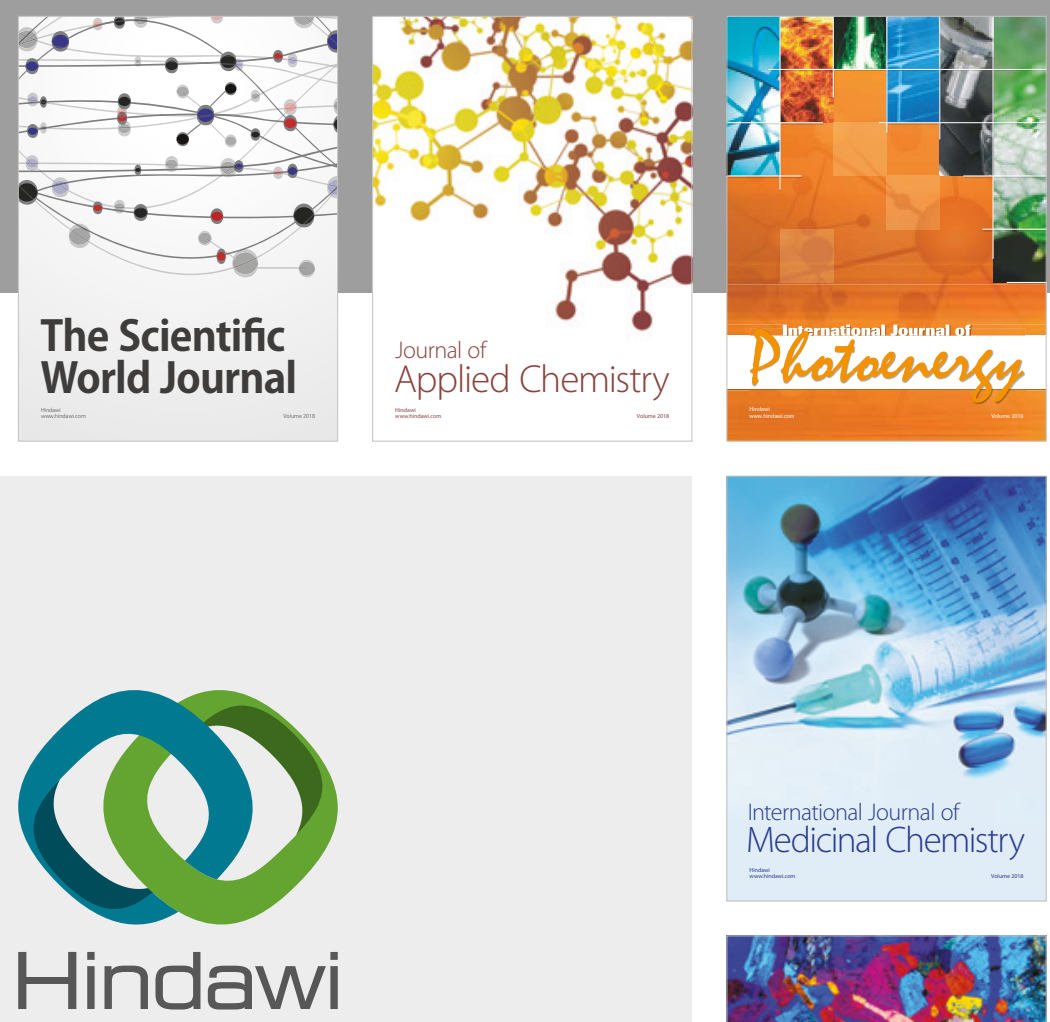

Submit your manuscripts at

www.hindawi.com
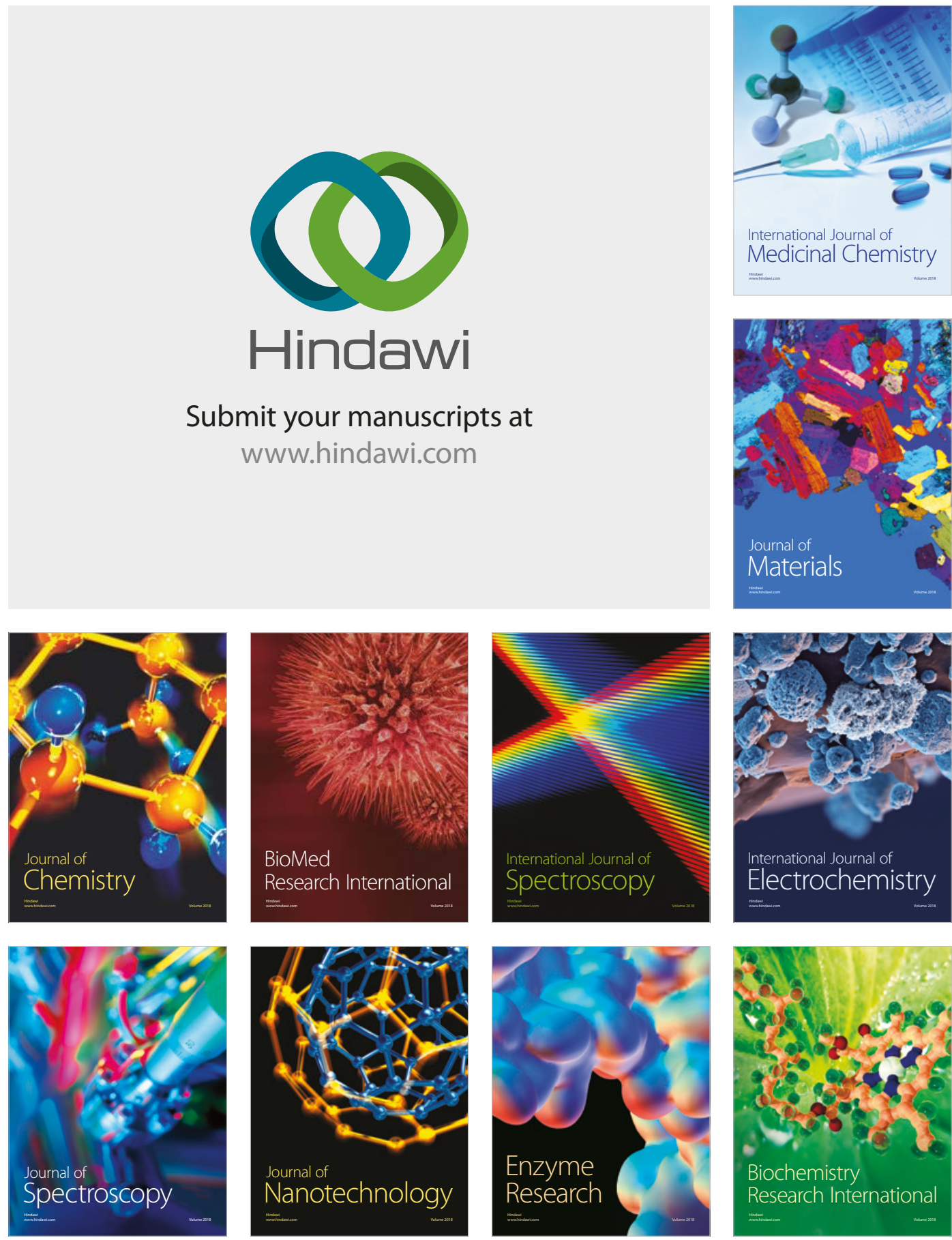
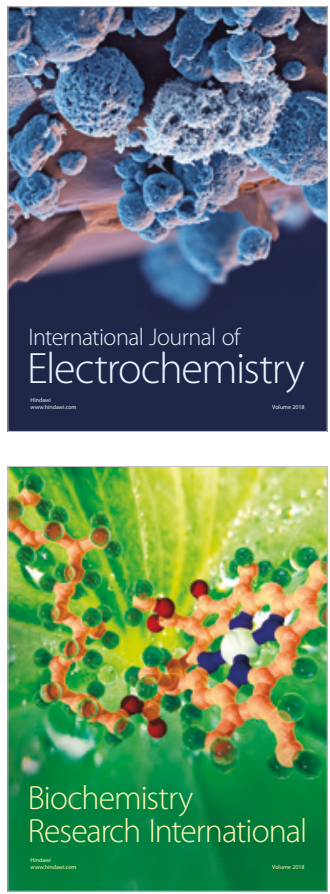